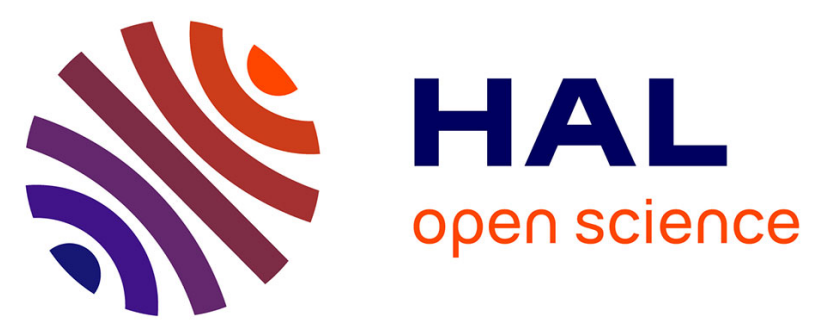

\title{
Surface morphology and thickness of a multilayer film composed of strong and weak polyelectrolytes: Effect of the number of adsorbed layers, concentration and type of salts
}

C.C. Buron, C. Filiâtre, F. Membrey, C. Bainier, L. Buisson, D. Charraut, A. Foissy

\section{To cite this version:}

C.C. Buron, C. Filiâtre, F. Membrey, C. Bainier, L. Buisson, et al.. Surface morphology and thickness of a multilayer film composed of strong and weak polyelectrolytes: Effect of the number of adsorbed layers, concentration and type of salts. Thin Solid Films, 2009, 517 (8), pp.2611-2617. 10.1016/j.tsf.2008.10.036 . hal-00447189

\author{
HAL Id: hal-00447189 \\ https://hal.science/hal-00447189
}

Submitted on 4 May 2021

HAL is a multi-disciplinary open access archive for the deposit and dissemination of scientific research documents, whether they are published or not. The documents may come from teaching and research institutions in France or abroad, or from public or private research centers.
L'archive ouverte pluridisciplinaire HAL, est destinée au dépôt et à la diffusion de documents scientifiques de niveau recherche, publiés ou non, émanant des établissements d'enseignement et de recherche français ou étrangers, des laboratoires publics ou privés. 


\title{
Surface morphology and thickness of a multilayer film composed of strong and weak polyelectrolytes: Effect of the number of adsorbed layers, concentration and type of salts
}

\author{
C.C. Buron ${ }^{\mathrm{a}, *}$, C. Filiâtre ${ }^{\mathrm{a}}$, F. Membrey $^{\mathrm{a}}$, C. Bainier ${ }^{\mathrm{b}}$, L. Buisson ${ }^{\mathrm{b}}$, D. Charraut $^{\mathrm{b}}$, A. Foissy $^{\mathrm{a}}$ \\ anstitut UTINAM-CNRS 6213, Université de Franche-Comté, 16 route de Gray, 25030 Besançon Cedex, France \\ b Institut FEMTO-ST, Département d'Optique P.M. Duffieux, CNRS-UMR 6174, Université de Franche-Comté, 16 route de Gray, 25030 Besançon Cedex, France
}

Self-assembled multilayered films were prepared by alternate deposition of a strong cationic polyelectrolyte, poly(trimethylammonium ethyl methacrylate chloride) and a pH-dependant anionic polyelectrolyte, poly (acrylic acid). The layer-by-layer adsorption was followed in-situ by optical fixed-angle reflectometry and after drying by ellipsometry. A recently developed "substrate thickness method" was applied to calculate the adsorbed amount of polymer from the reflectometric signal. Surface film morphology was imaged before and after drying with atomic force microscopy (AFM). Influence of the number of adsorbed layers, concentration and type of salts on the multilayer growth was examined. The number of adsorbed layers produced a specific effect on the reflectometric signal which is linked to the refractive index of the film. Adjustment of the adsorbed amount of polyelectrolytes was done by changing sodium chloride salt concentration within a range of $10^{-3}$ to $10^{-1} \mathrm{M}$. AFM observations showed a significant evolution in surface morphology and a maximum of surface roughness for films built-up at $10^{-2} \mathrm{M}$. Experiments were then carried out at $10^{-3} \mathrm{M}$ i n either barium chloride or zinc chloride salts. In the presence of $\mathrm{Ba}^{2+}$ and $\mathrm{Zn}^{2+}$ ions, adsorption of 5 bilayers is completely modified and the surface morphology was smoother than the multilayers obtained using sodium chloride salt.

\section{Introduction}

Functional films with targeted properties can be produced by the layer-by-layer adsorption technique. This self-assembled method is based on the alternate adsorption of oppositely charged polyelectrolytes on charged surfaces [1]. Versatility, simplicity and flexibility of the build-up process are the main advantages of this deposition technique. Numerous substrates (colloid particle, silicon wafer, glass slide, metal) are suitable for the growth of multilayered film. Incorporation of small species such as conductive polymers, dyes, proteins and inorganic particles in polyelectrolyte multilayer leads to functional film for potential applications in optics, biosensors, microelectronics... [2] Moreover, multilayered film can be used directly as a composite membrane for filtering with no additional material [3-6]. Polyelectrolyte multilayered membranes have many applications in pervaporation, ion permeation, water purification... [7-11] Ouyang et al. [12] recently showed the importance of controlling film properties on the final permeation capacity of membranes composed of five bilayers of poly(stryrene sulfonate)

\footnotetext{
* Corresponding author. Tel.: +33 381662048.

E-mail address: cedric.buron@univ-fcomte.fr (C.C. Buron).
}

and poly(allylamine hydrochloride). The separation performance was optimised by the controlling $\mathrm{pH}$ and supporting electrolyte concentration when preparing the film. Encapsulation is another way to use multilayered film where the choice of the polyelectrolytes - and especially the charged chemical function - is essential in the final application $[13,14]$. An example of this is the release of encapsulated material, which depends mainly on the capacity of the polymer chain network to evolve when a change in $\mathrm{pH}$ is applied [15,16]. Targeted film properties are therefore linked with the preparation process.

In the present work, we investigate the effect of several physicochemical parameters on the morphological properties of a multilayered film composed of a strong cationic polyelectrolyte (poly (trimethylammonium ethyl methacrylate chloride)) and a weak anionic polyelectrolyte (poly(acrylic acid)). Effect of the number of adsorbed layers, sodium salt concentration and the nature of the ion of the electrolyte was examined using in-situ optical fixed-angle reflectometry, ellipsometry and atomic force microscopy (AFM). Adsorbed amount, refractive index and thickness were calculated from reflectometric measurements and compared to those obtained by ellipsometry. Topographical AFM images of the multilayer surface deposited onto silicon substrate were carried out before and after drying. Physicochemical parameter adjustment was found to lead to morphological film variation. 


\section{Experimental details}

\subsection{Materials}

Quaternized poly(dimethylaminoethyl methacrylate chloride) (MADQUAT) (Mw: $30000 \mathrm{Da}$ ) and poly(acrylic acid) (PAA) (Mw: $10000 \mathrm{Da}$ ), illustrated in Fig. 1, were synthesized by COATEX (France). MADQUAT is a strong cationic polyelectrolyte whereas PAA is a weak anionic polyelectrolyte, with an intrinsic ionization $\mathrm{pK}$ of 5 in $10^{-3} \mathrm{M}$ $\mathrm{NaCl}$ solution and an ionization ratio about 0.25 at the experimental $\mathrm{pH} 5.5$ [17]. The refractive index increment $(\mathrm{d} n / \mathrm{d} c$ where $n$ is the refractive index of the solution and $c$ the concentration of polymer) of each polyelectrolyte in water was determined with a Mettler Toledo refractometer RE50. It was equal to $0.192 \mathrm{~cm}^{3} \mathrm{~g}^{-1}$ for MADQUAT and $0.201 \mathrm{~cm}^{3} \mathrm{~g}^{-1}$ for PAA. $\mathrm{NaCl}, \mathrm{BaCl}_{2}$ and $\mathrm{ZnCl}_{2}$ salts were purchased from Aldrich. Polyelectrolyte solutions at a concentration of $10 \mathrm{mg} \mathrm{L}^{-1}$ were prepared immediately prior to each experimental series. All experiments were carried out at $\mathrm{pH} 5.5$ and $20^{\circ} \mathrm{C}$.

\subsection{Multilayer deposition}

A silicon wafer (ACM, France) covered with a thin silicon oxide layer of variable thickness was used as a substrate. The wafers were cleaned with piranha solution ( $7: 3 \mathrm{v} / \mathrm{v} \mathrm{H}_{2} \mathrm{SO}_{4} 98 \%$ and $\mathrm{H}_{2} \mathrm{O}_{2} 32 \%$ mixture) prior to polyelectrolyte adsorption, extensively washed with ultrapure water $(18.2 \mathrm{M} \Omega \mathrm{cm})$ and stored in water until use. Multilayers were built in the reflectometer cell by alternative injection of polyelectrolyte solution every $10 \mathrm{~min}$. There was no washing between deposition cycles. Due to the negative charge of silicon oxide surface at $\mathrm{pH}$ 5.5, MADQUAT was always injected first.

\subsection{Spectroscopic ellipsometry}

A spectroscopic phase-modulated ellipsometer (Jobin Yvon, Model UVISEL) was used to measure thickness of the silicon oxide layer and the multilayered film after drying. Thickness was determined from the experimental values $\Psi$ and $\Delta$, where $\Psi$ is the azimuth angle of the amplitude ratio for polarized parallel and normal to the plane of incidence and $\Delta$ is the relative phase difference. Experiments were carried out at a $70^{\circ}$ incidence angle in the spectral range.

\subsection{Optical fixed-angle reflectometry}

A homemade optical fixed-angle reflectometer equipped with an impinging jet cell $[18,19]$ was used to investigate in-situ alternate

\section{MADQUAT}

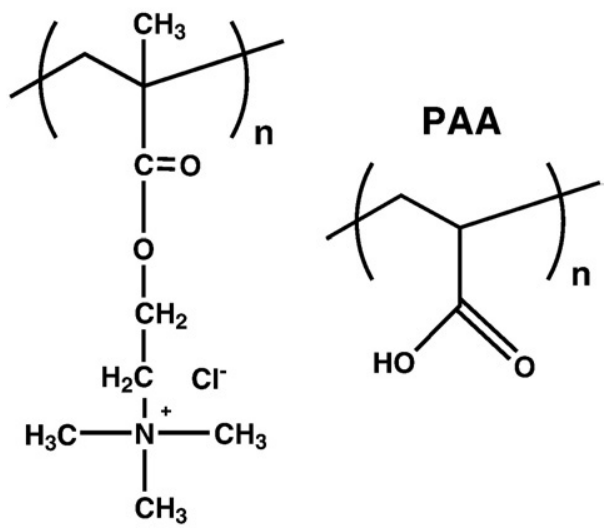

Fig. 1. Structural formulas of the cationic polymer quaternized poly(dimethylaminoethyl methacrylate chloride) (MADQUAT) and the anionic polymer poly(acrylic acid) (PAA).

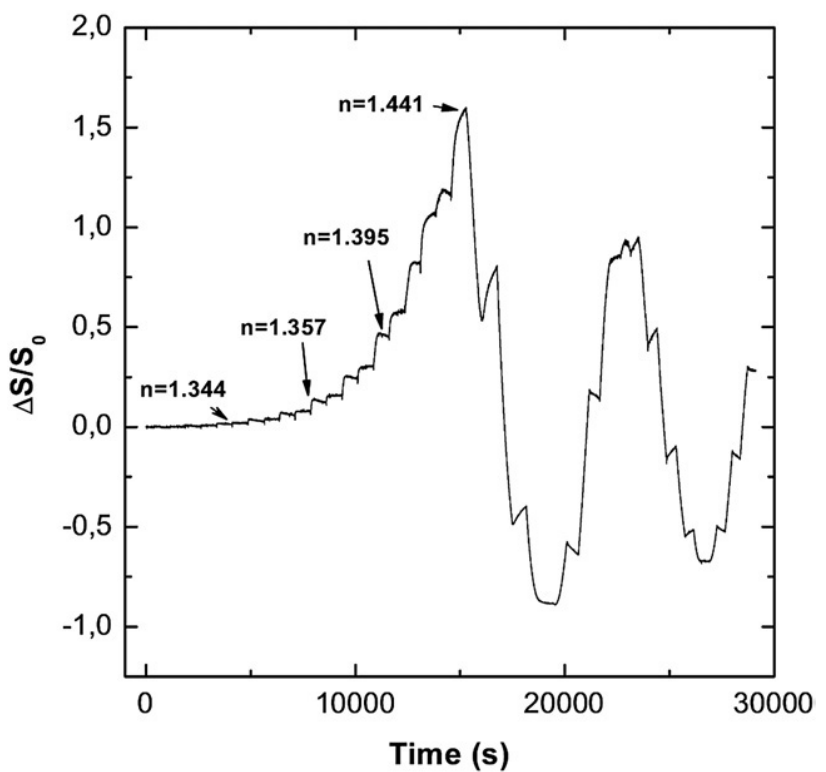

Fig. 2. Reflectometric output variation recorded during the build-up of 24 MADQUAT/PAA bilayers onto silicon oxide $\left(d_{\mathrm{SiO}_{2}} 98.7 \mathrm{~nm}, \mathrm{pH} 5.5, \mathrm{Cp} 0.01 \mathrm{~g} \mathrm{~L}^{-1}, C_{\mathrm{NaCl}} 10^{-3} \mathrm{M}\right)$.

polyelectrolyte adsorption. Signals recorded during the injection of polyelectrolyte-free solution and polyelectrolyte solution are symbolized respectively by $S_{0}$ and $S$. The relative variation of the reflectometric signal $\left(S-S_{0}\right) / S_{0}$ represents, at least semi-quantitatively, the variation of the adsorbed amount [20]. In a previous study we demonstrated that the reflectometric signal of multilayers adsorbed onto gold substrate was proportional to the surface excess up to about $10 \mathrm{mg} \mathrm{m}^{-2}$ [21]. In a subsequent study, we determined the precise amount adsorbed onto silicon substrate [22]. The basic principle of the method we used was to perform similar deposition experiments (i.e. assumed similar deposited amounts) onto substrates of a same chemical nature but with different thicknesses. Experiments were then carried out under the same experimental conditions on silicon wafers coated with silicon oxide substrates of different thicknesses (52.9, 98.7, 138.5, $163.5 \mathrm{~nm}$ ). The refractive index and the thickness of the adsorbed layer were determined from the reflectometric signals $\Delta S / S_{0}$ and the polymer uptake was deduced using De Feijter's formula [23].

\subsection{Atomic force microscopy}

The scanning probe microscope used was a commercial Atomic Force Microscope manufactured by NT-MDT with a measuring head SMENA. The probe had a curvature of about $10 \mathrm{~nm}$, a tip $10-20 \mu \mathrm{m}$ in height and a cone angle less than $22^{\circ}$. The resonant frequency of the cantilever was $255 \mathrm{kHz}$. AFM images of the multilayer surfaces were obtained in the liquid state, directly after the build-up of multilayers in the reflectometer. The samples were then dried and scanned again. Images were captured in contact mode for the liquid state and in tapping mode for the dry state.

\section{Results and discussion}

\subsection{Effect of the number of adsorbed layers}

\subsubsection{Reflectometry and ellipsometry investigations}

The amount of polymer adsorbed onto silicon oxide substrate was first tuned by changing the number of adsorbed layers. Fig. 2 depicts this effect on reflectometric output $\left(\Delta S / S_{0}\right)$ for 24 MADQUAT/PAA bilayers adsorbed on silicon oxide surface. After each injection of polymer solution a common reflectometric signal, i.e. an increase of the signal which tends to a plateau, was recorded up to deposition of 
ten bilayers. This corresponds to a progressive increase in adsorbed polymeric materials at the silicon oxide/solution interface. From this point on, $\Delta S / S_{0}$ decreased in spite of the expected polyelectrolyte adsorption and globally oscillates in function of the number of adsorbed layers. The same was observed during multilayer adsorption onto silicon oxide film 52.9, 138.5, and $163.5 \mathrm{~nm}$ thick. In order to determine the refractive index and the thickness of the deposited polyelectrolyte film, our substrate thickness method, based on experimental reflectometric signal comparison, was applied for the first ten bilayers. Indeed, reflectometric signals do not reach a plateau during the output oscillations - especially during MADQUAT adsorption; this induces experimental uncertainty on calculated values. A gradual increase in the refractive index from the first to the tenth bilayer was found from a value close to the water refractive index (1.333) to the value of 1.441 (see Fig. 2). Moreover, the refractive index of the film cannot exceed the value of mixture of the two bulky polymers. Refractometry measurements (Mettler Toledo RE 50) of a polyelectrolyte solution concentrated at $210 \mathrm{~g} \mathrm{~L}^{-1}$ showed a refractive index of 1.382 for MADQUAT solution and 1.412 for PAA solution. These values concur with the refractive index of 1.45 , generally given in the literature as a reference for the refractive index of a polymeric layer; this index is commonly used in optical models to determine the thickness of polymer film from mono-wavelength ellipsometric measurements $[24,25]$. In order to ascertain the thickness of the polymer-layered film up to 20 layers, spectroscopic ellipsometry measurements were performed on dry samples. Fig. 3 shows the evolution of a non linear thickness along the build-up of 40 deposited layers. Reflectometry measurements indicated the same thickness as that obtained by ellipsometry.

Oscillations of the reflectometric signal $(S)$ are due to the dependence of the phase difference on both the thickness and the refractive index of the adsorbed layer, which change in the course of the multilayer construction. In fact, the $S$ signal is proportional to the ratio of the parallel $\left(R_{\mathrm{p}}\right)$ and perpendicular $\left(R_{\mathrm{s}}\right)$ reflectivities of the interface [18] which depend on the cosine of the phase difference $\left(\Phi_{\mathrm{a}}\right)$ in the adsorbed layer, given by:

$\Phi_{\mathrm{a}}=\frac{2 \pi \cdot d_{\mathrm{a}} \cdot n_{\mathrm{a}} \cdot \cos \theta_{\mathrm{a}}}{\lambda}$

where $d_{\mathrm{a}}$ and $n_{\mathrm{a}}$ are respectively the thickness and the refractive index of the adsorbed layer and $\lambda$ is the laser wavelength. The $\theta_{\mathrm{a}}$ angle

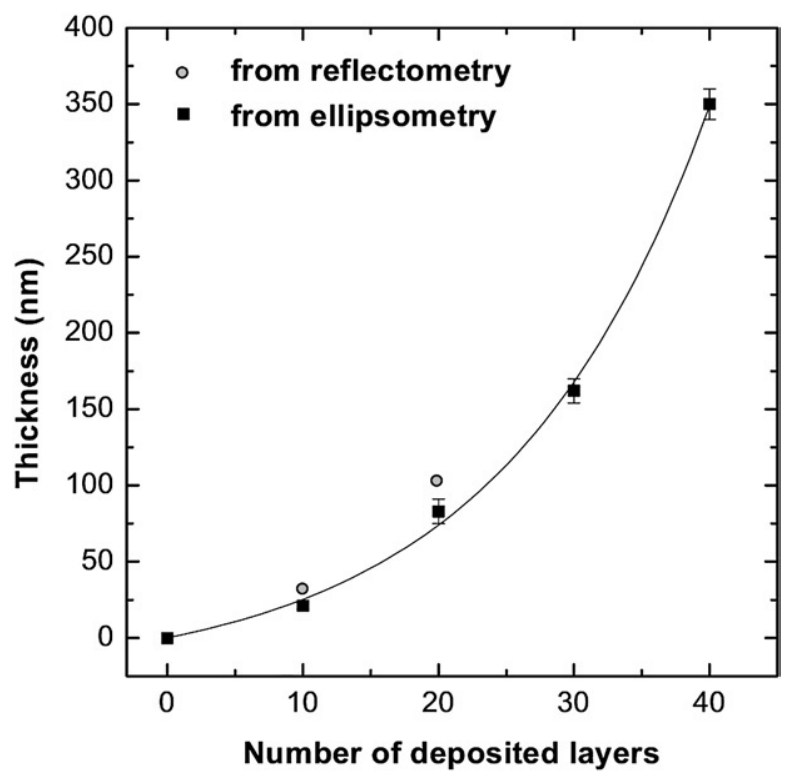

Fig. 3. Thickness variation for MADQUAT/PAA multilayered film deposited onto silicon oxide ( $d_{\mathrm{SiO}_{2}} 98.7 \mathrm{~nm}$, pH 5.5, Cp $\left.0.01 \mathrm{~g} \mathrm{~L}^{-1}, C_{\mathrm{NaCl}} 10^{-3} \mathrm{M}\right)$.
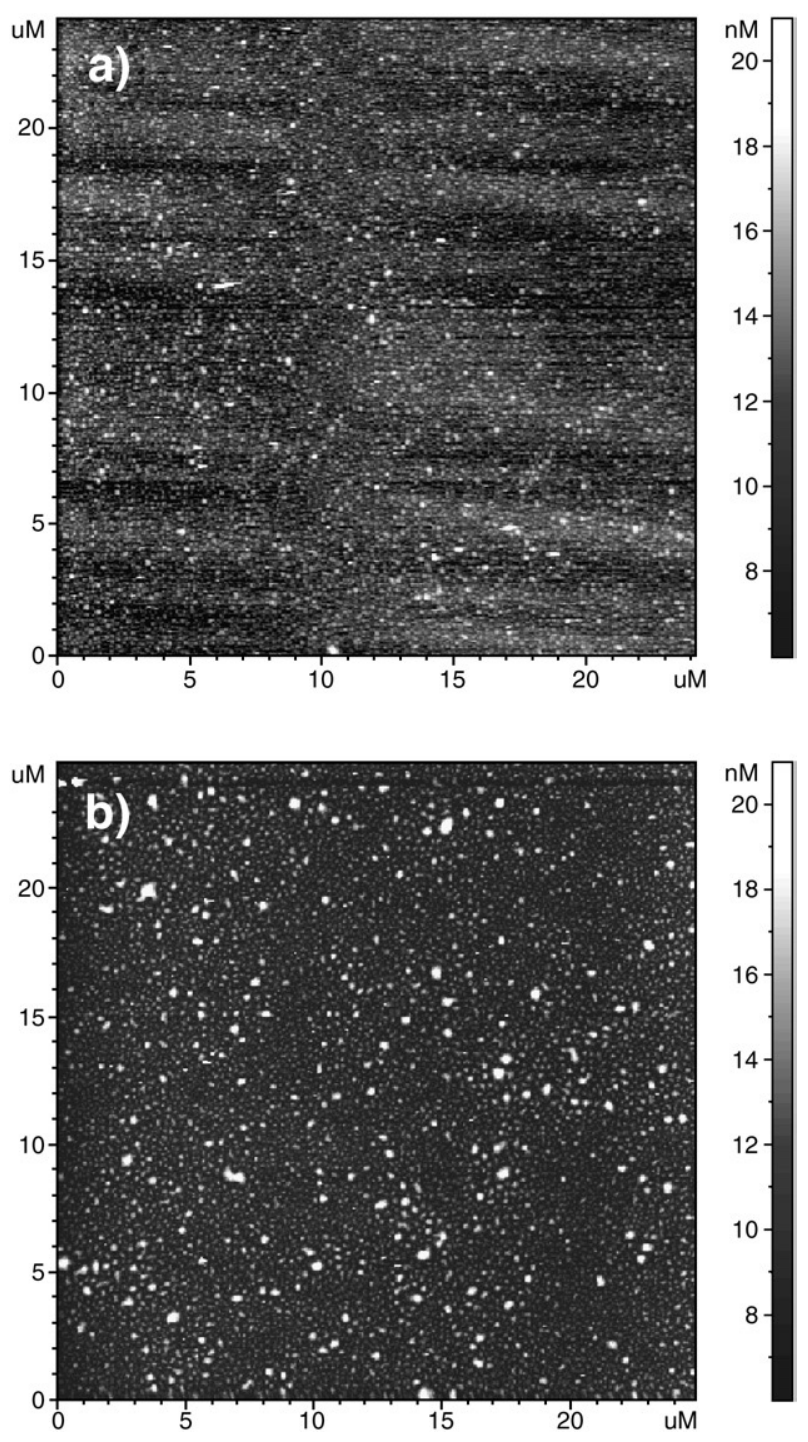

Fig. 4. AFM topographical images $\left(25 \times 25 \mu \mathrm{m}^{2}\right)$ of 5 MADQUAT/PAA bilayers before (a) and after (b) drying $\left(d_{\mathrm{SiO}_{2}} 98.7 \mathrm{~nm}, \mathrm{pH} 5.5, \mathrm{Cp} 0.01 \mathrm{~g} \mathrm{~L}^{-1}, C_{\mathrm{NaCl}} 10^{-3} \mathrm{M}\right)$.

can be calculated from the incidence angle using Snell's law. Considering a maximum threshold for the refractive index of the adsorbed layer, reflectivity and hence reflectometric signals become a periodical function of film thickness, which leads to oscillations in the recorded signal for thick multilayers. Other works using in-situ techniques such as optical waveguide lightmode spectroscopy have also shown a stabilisation of the refractive index for poly(L-lysine)/ hyaluronic acid multilayers [26] and for a mixture of poly(glutamic acid)-poly(styrene sulfonate)/poly(allylamine hydrochloride) multilayers [27]. Experimentally, diffusion of the laser beam becomes more and more visible along the multilayer adsorption, which explains the decrease in signal oscillations. Diffusion can be due to several factors such as increased surface roughness or a variation in the refractive index within the film (aggregates).

\subsubsection{Atomic force microscopy investigations}

The progressive aspect of film topography between 5 and 20 bilayers after drying was investigated by AFM measurements in a previous study [28]. The same liquid state observations allowed us to exclude the drying step in the formation of the surface morphology (Fig. $4 a$ and b). As mentioned in our previous article, imaging of the surface after adsorption of 5 bilayers revealed numerous small peaks. With the increase of adsorbed layers (10 to 20 bilayers), the peaks 


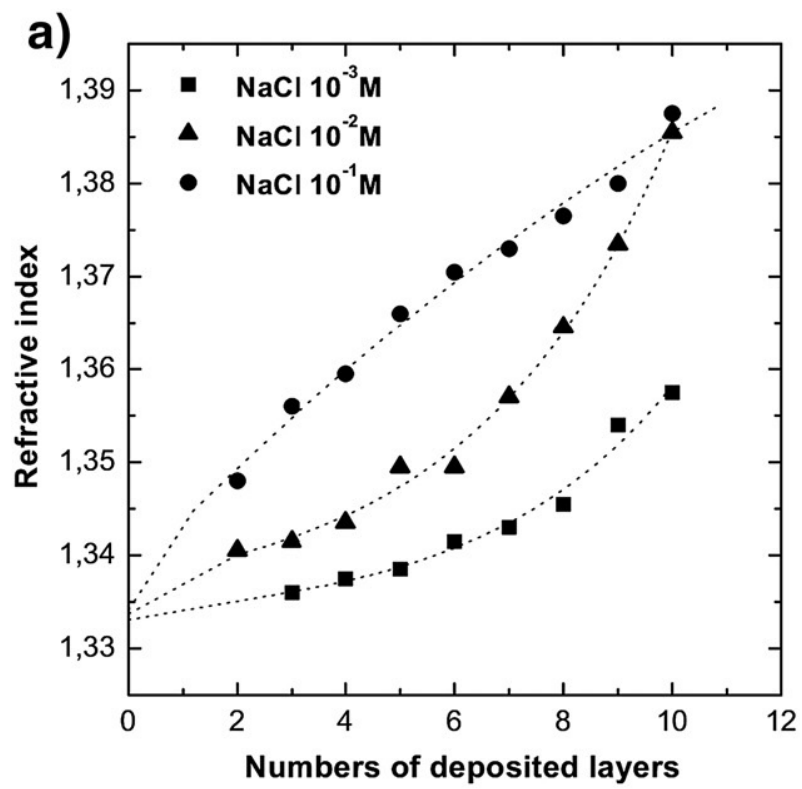

b)

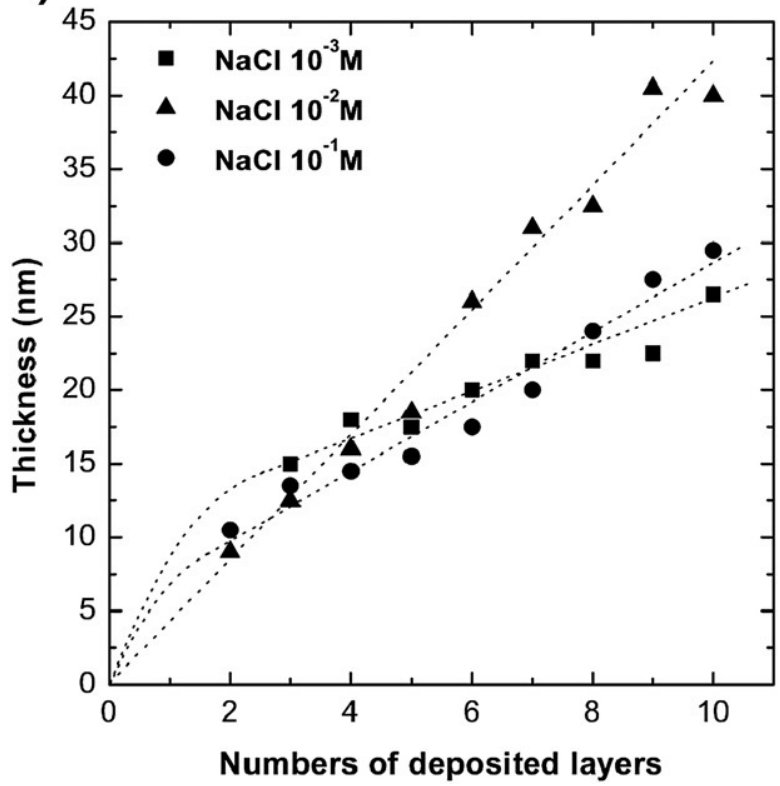

Fig. 5. Evolution of (a) refractive index and (b) thickness from reflectometric measurements and our substrate thickness method for MADQUAT/PAA bilayers builtup from different $\mathrm{NaCl}$ concentrations. Experimental uncertainty for the refractive index is $+/-0.002$ and $+/-1.5 \mathrm{~nm}$ for thickness $\left(d_{\mathrm{SiO}_{2}} 98.7 \mathrm{~nm}, \mathrm{pH} 5.5, \mathrm{Cp} 0.01 \mathrm{~g} \mathrm{~L}^{-1}\right)$.

became wider and the film progressively smoother as the valleys filled in. Nevertheless, a few cavities remained. A mechanism based on patches of polyelectrolyte adsorption was proposed to explain this multilayer morphology [29]. Similar pictures taken by Picart et al. [26] showed a progressive transition from an island-like structure to a uniform film after a six-bilayer deposition of a poly(L-lysine)/ hyaluronic acid pair on a glass substrate.

In the present paper, AFM observations provide information on results monitored by reflectometric measurements, especially on refractive index variation. Indeed, for 5 deposited bilayers, the "optical layer" investigated by laser beam is composed by polymeric peaks surrounded by water, leading to a small value of the refractive index. Thickness measurements from reflectometry and ellipsometry corroborate AFM images exhibiting peaks of $18 \mathrm{~nm}$ in height. When the number of adsorbed layers increases, the valleys are progressively filled by polymer and the refractive index increases due to the decrease in water content in the "optical layer". For 20 bilayers, the "optical layer" is composed almost completely of polymer, which gives it a value of 1.44 - close to that of a "pure" layer of polymeric material.
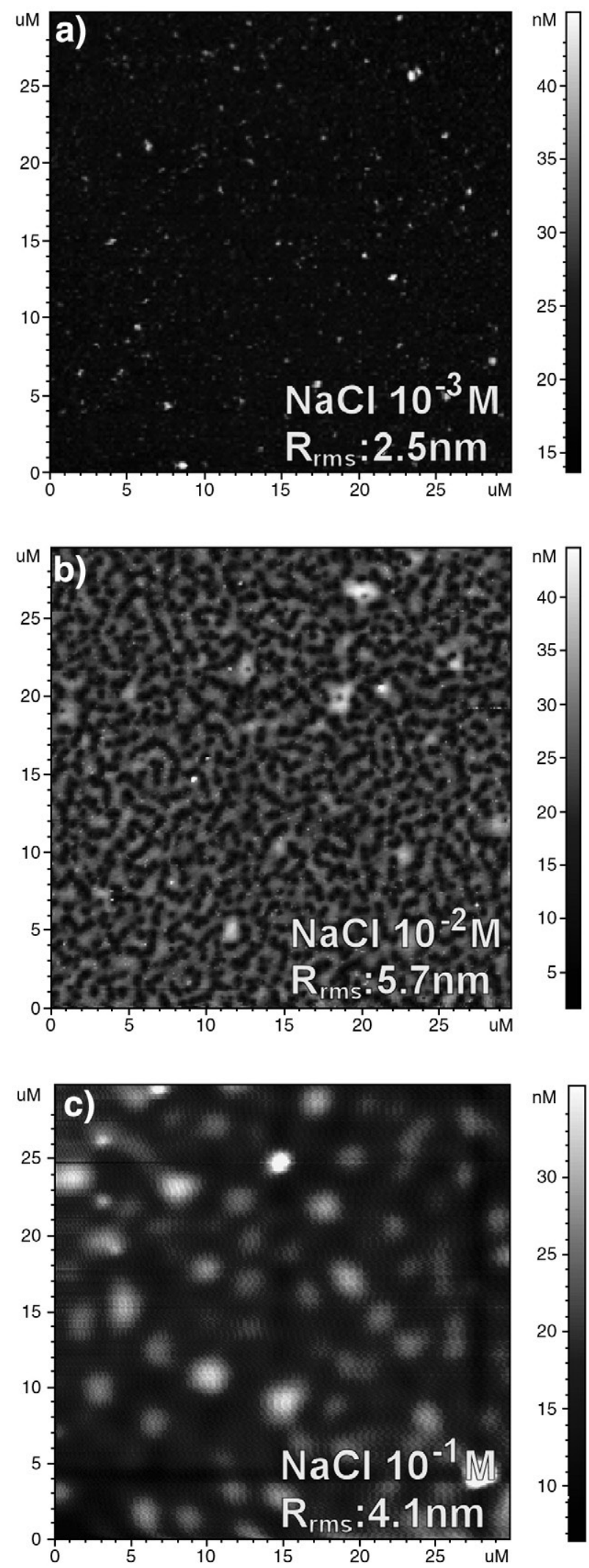

Fig. 6. AFM topographical images $\left(30 \times 30 \mu \mathrm{m}^{2}\right)$ of 5 MADQUAT/PAA bilayers built-up from different $\mathrm{NaCl}$ concentrations $\left(10^{-3} \mathrm{M}, 10^{-2} \mathrm{M}\right.$ and $\left.10^{-1} \mathrm{M}\right) . R_{\mathrm{rms}}$ represents the root-mean-square roughness $\left(d_{\mathrm{SiO}_{2}} 98.7 \mathrm{~nm}, \mathrm{pH} 5.5, \mathrm{Cp} 0.01 \mathrm{~g} \mathrm{~L}^{-1}\right)$. 

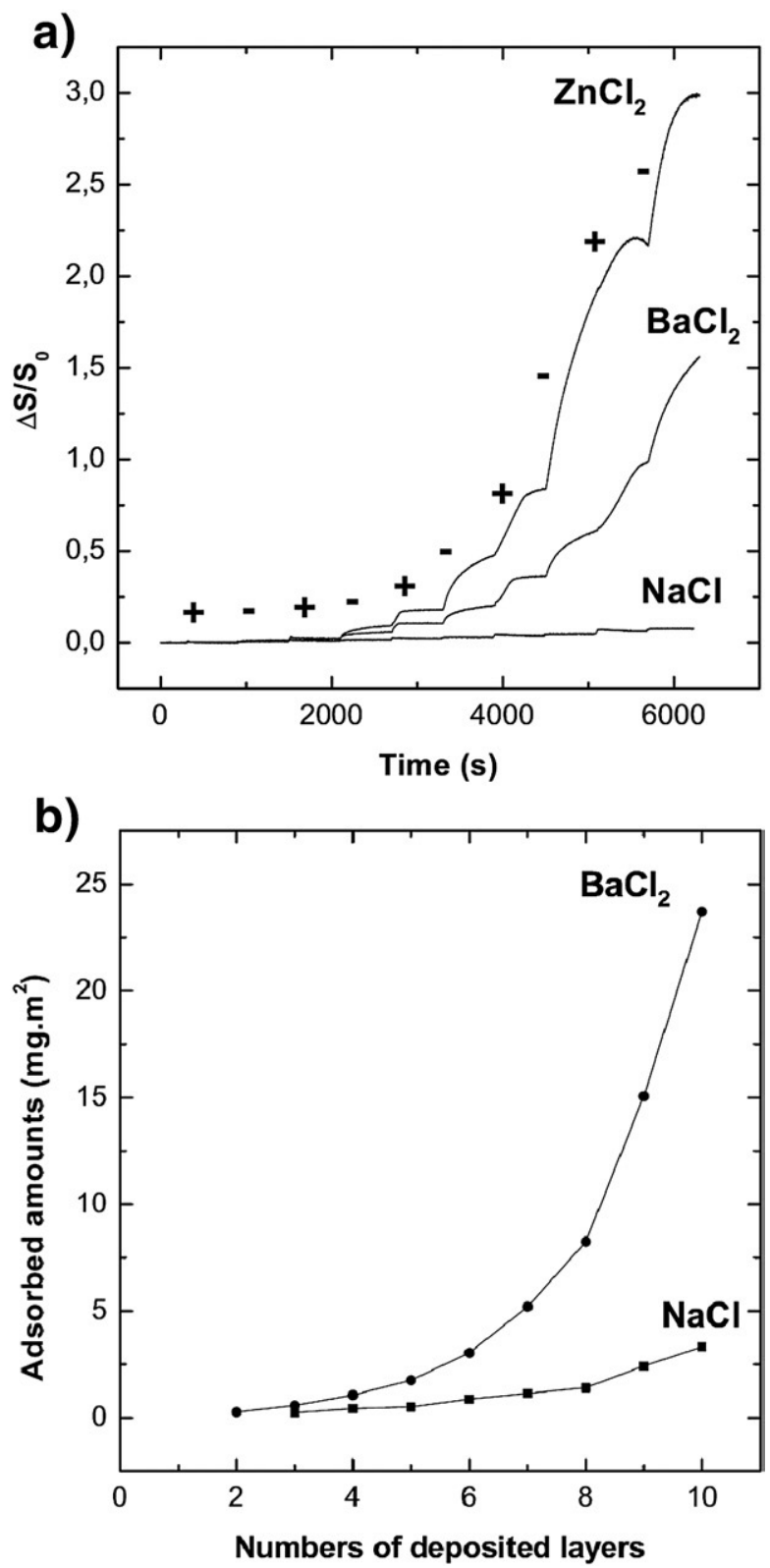

Fig. 7. Effect of divalent cations on the adsorption of 5 MADQUAT/PAA bilayers: (a) reflectometric and (b) polymer uptake variations. Experimental uncertainty for adsorbed amount is $+/-0.5 \mathrm{mg} \mathrm{m}^{-2}\left(d_{\mathrm{SiO}_{2}} 98.7 \mathrm{~nm}\right.$, pH 5.5, Cp $\left.0.01 \mathrm{~g} \mathrm{~L}^{-1}, C_{\text {salt }} 10^{-3} \mathrm{M}\right)$.

The number of adsorbed layers is a simple physical parameter to adjust deposited film properties. MADQUAT/PAA multilayered film with high surface roughness can be obtained when few polyelectrolyte layers are deposited. At the opposite, thick multilayered film (around $400 \mathrm{~nm}$ ) exhibits a low surface roughness.

\section{Effect of $\mathrm{NaCl}$ concentration}

To further explore the variation in adsorbed amounts in function of physicochemical parameters, the build-up of multilayers was examined by varying $\mathrm{NaCl}$ concentration. Fig. $5 \mathrm{a}$ and $\mathrm{b}$ represent refractive index and thickness variations during the build-up of 5 MADQUAT/PAA bilayers. Refractive indexes evolve exponentially at a salt concentration of $10^{-3} \mathrm{M}$ and $10^{-2} \mathrm{M}$ whereas a quasi-linear evolution is observed at $10^{-1} \mathrm{M}$. The increase in film thickness at $10^{-3} \mathrm{M}$ is similar to that at $10^{-1} \mathrm{M}$, but greater at $10^{-2} \mathrm{M} \mathrm{NaCl}$. Generally speaking, variation in film thickness seems to vary linearly with the number of adsorbed layers whatever the salt concentration. De Feijter's formula [23] was used to calculate polymer uptake from thickness and refractive index values for 10 adsorbed layers. A maximum of $10.8 \mathrm{mg} \mathrm{m}^{-2}$ of adsorbed polymer uptake was found for the $10^{-2} \mathrm{M} \mathrm{NaCl}$ solution, 8.3 and $3.3 \mathrm{mg} \mathrm{m}^{-2}$ for $10^{-1} \mathrm{M}$ and $10^{-3} \mathrm{M} \mathrm{NaCl}$ solutions respectively.

Salt concentration is known to have a strong effect on polymer adsorption [30]. On the one hand, due to a screening of polymer charges by salt ions, the conformation of the polymer chain in solution changes from an extended to a globular shape with an increase in salt concentration [31]. On the other hand, adsorption of charged polyelectrolytes is kinetically limited by an electrostatic barrier that takes place between the previously deposited molecules and the incoming macromolecules [32]. At high salt concentration, more molecules are needed to reach the barrier due to the screening of polymer charges. The increase in polymer uptake of MADQUAT/PAA multilayer built with a $\mathrm{NaCl}$ concentration of $10^{-2} \mathrm{M}$ confirms these findings. However above a salt concentration threshold between $10^{-2} \mathrm{M}$ and $10^{-1} \mathrm{M}$, adsorption governed by electrostatic interactions decreases despite the increase in salt concentration. With a high salt concentration, polyelectrolyte adsorption probably depends on the competition between the small ions of the electrolyte and the ionized groups of the polyelectrolyte in order to bind with the charged groups on surface. This type of effect was reported in a previous paper addressing the effect of $\mathrm{pH}$ and monovalent
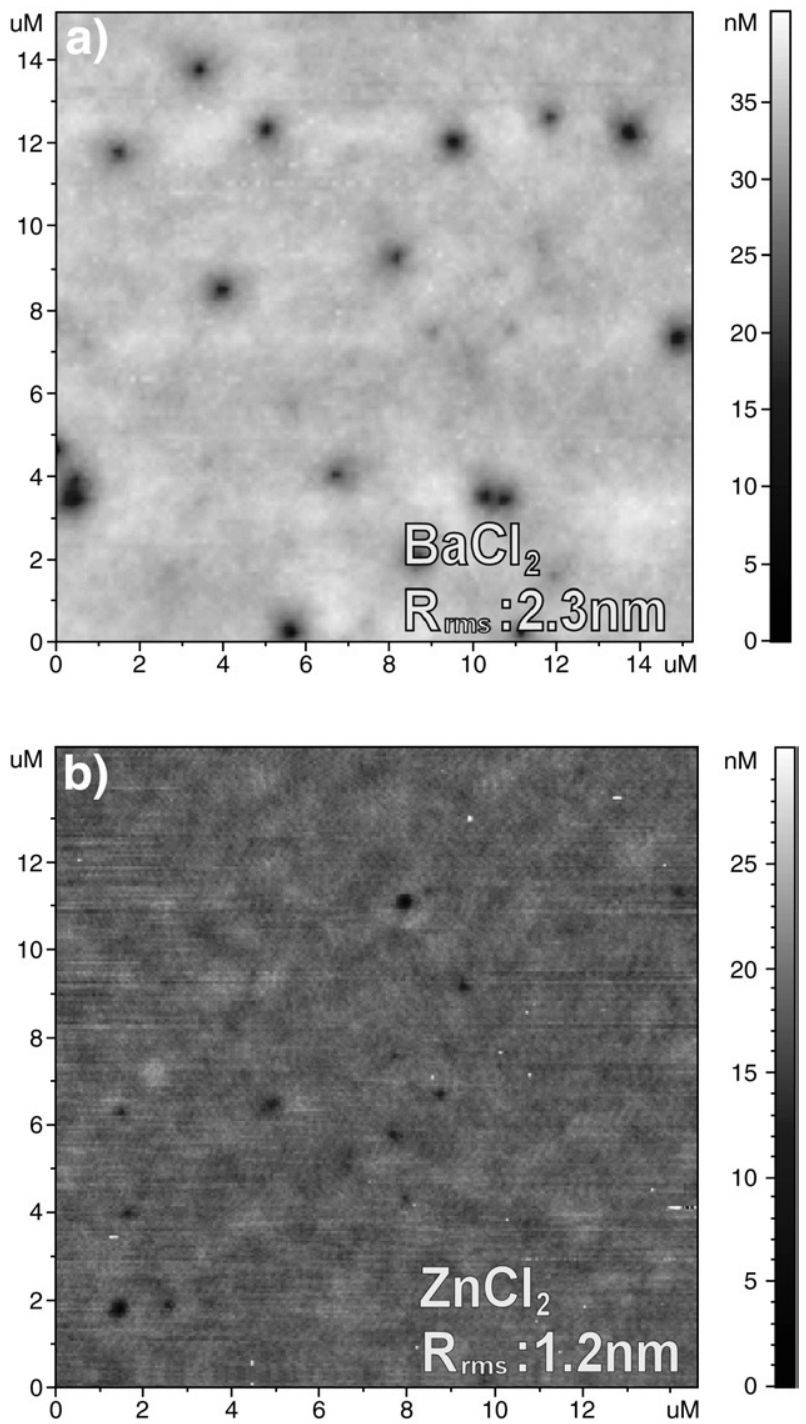

Fig. 8. AFM topographical images $\left(15 \times 15 \mu \mathrm{m}^{2}\right)$ of 5 MADQUAT/PAA bilayers deposited onto silicon oxide from $10^{-3} \mathrm{M}$ in $\mathrm{BaCl}_{2}$ (a) and $\mathrm{ZnCl}_{2}$ (b). $R_{\mathrm{rms}}$ represents the rootmean-square roughness $\left(d_{\mathrm{SiO}_{2}} 98.7 \mathrm{~nm}, \mathrm{pH} \mathrm{5.5,} \mathrm{Cp} 0.01 \mathrm{~g} \mathrm{~L}^{-1}\right)$. 
ions on the charge densities in each layer; here, we showed that the charge balance revealed a large ratio of compensation of PAA with $\mathrm{Na}^{+}$in the case of film built-up at $10^{-1} \mathrm{M} \mathrm{NaCl}$ [29].

Atomic force microscopy investigations showed the same salt concentration threshold (Fig. 6). At $10^{-3} \mathrm{M}$, the surface was covered with small peaks $30 \mathrm{~nm}$ high, while the build-up at $10^{-2} \mathrm{M}$ lead to a vermiculated morphology with peaks $37 \mathrm{~nm}$ high and about $1 \mu \mathrm{m}$ wide. Films prepared at $10^{-1} \mathrm{M}$ showed a granular texture with a few globular peaks (2-3 $\mu \mathrm{m}$ wide) dispersed on the surface. The observed changes in surface morphology were also reflected in the multilayer surface roughness. From $10^{-3}$ to $10^{-2} \mathrm{M}$, film roughness increased but then decreased for $10^{-1} \mathrm{M}$. McAloney et al. [33] observed a progressive increase in surface roughness during PDDA/PSS multilayer formation in function of salt concentration, but no diminution after a salt concentration threshold. This is probably due to the polyelectrolyte couple used: a strong/strong polyelectrolyte pair. In our experiments, PAA was a weak polyelectrolyte with a very low charge density at $\mathrm{pH}$ 5.5 ( $\mathrm{pKa} \approx 5$ depending on salt concentration). For the same salt concentration and at $\mathrm{pH}$ 5.5, PAA adopts a more globular coil conformation than PSS due to the charge density difference. Schoeler et al. showed the influence of both charge densities and salt concentration on the growth and surface topography of multilayers using different cationic polymer with charge densities from $100 \%$ to 25\% [34]: an increase in both salt concentration and charge density produced thicker and rougher films.

The unusual evolution of the amount adsorbed according to salt concentration can be explained by the difference in behaviour between MADQUAT and PAA, especially their conformation in the bulk polyelectrolyte solution before adsorption, when the same salt concentration is used.

\section{Effect of divalent salt}

The last physicochemical parameter studied was the nature of the counterion and more precisely the effect of divalent cations on multilayer adsorption. In a previous paper addressing the effect of monovalent counterions on polyelectrolyte multilayer adsorption, we observed that polymer uptake was linked to the place of counterion in the Hofmeister series, hence to the ability of the counterion to screen polyelectrolyte charges. To improve screening, low concentrations $\left(10^{-3} \mathrm{M}\right)$ of divalent salts were used. The reflectometric signal variations depicted in Fig. 7a show divalent ions to have a strong influence on the amount of polymer adsorbed. Whatever the nature of the divalent ion $\left(\mathrm{Ba}^{2+}\right.$ or $\left.\mathrm{Zn}^{2+}\right)$, output signals are higher than for sodium counterions. Our substrate thickness method was applied to quantify these variations in the case of experiments carried out in the presence of $\mathrm{BaCl}_{2}$. The amount adsorbed (Fig. 7b) after 5 deposited bilayers of MADQUAT/PAA was $23.7 \mathrm{mg} \mathrm{m}^{-2}$ with $\mathrm{Ba}^{2+}$ compared to $3.3 \mathrm{mg} \mathrm{m}^{-2}$ in the presence of $\mathrm{Na}^{+}$. Polymer uptake is therefore multiplied by seven when barium ions are used as counterions. We also observed that the output signal did not reach a plateau after the 6 th adsorbed layer for $\mathrm{Zn}^{2+}$ or the 8th for $\mathrm{Ba}^{2+}$, due to a set adsorption time. The adsorption kinetics differed in the presence of divalent cations and the electrokinetic barrier was not reached after $10 \mathrm{~min}$. Increased injection time for each step would probably lead to a higher adsorbed amount.

This noteworthy effect can be attributed to a stronger interaction between the anionic polyelectrolyte (PAA) and the cationic ions. From the ratio between the bound $\mathrm{Ba}^{2+}$ ions and the concentration of polyacrylate ions, Pochard et al. [35] showed that the complex between them is bidentate. Therefore, divalent ions are more efficient than monovalent ions. However ionic charge cannot explain the difference in adsorption when barium or zinc ions are used. Multilayer adsorption is lower when $\mathrm{Ba}^{2+}$ is used. Interactions between PAA charges and divalent ions seem to vary with the nature of the ions. Koda et al. [36] used Raman spectroscopy to confirm that interactions between $\mathrm{Zn}^{2+}$ and poly(acrylic acid) are stronger than for $\mathrm{Ba}^{2+}$ and PAA. Interaction with $\mathrm{Zn}^{2+}$ is dominated by specific interactions with bond formation whereas electrostatic interactions are dominant in the case of $\mathrm{Ba}^{2+}$.

Images of multilayer built-up with $\mathrm{Ba}^{2+}$ counterions show a relatively planar surface with holes $40 \mathrm{~nm}$ deep (Fig. 8a). $\mathrm{Zn}^{2+}$ produces the same effect but with a decrease in the number of holes (Fig. 8b). As opposed to the effect of salt concentration and in spite of the increase in adsorbed amount, the root-mean-square roughness showed a gradual surface smoothing in the following counterion series: $\mathrm{Na}^{+}>\mathrm{Ba}^{2+}>\mathrm{Zn}^{2+}$. The use of divalent ions therefore seems to act like the number of adsorbed layers. Fewer adsorbed layers are needed with divalent ions for a similar surface morphology. However multilayered film remains thicker when only the number of adsorbed layers changes.

AFM observations coupled with the substrate thickness method support these results. A low refractive index was determined for 5 deposited MADQUAT/PAA bilayers with $10^{-3} \mathrm{M} \mathrm{NaCl}(n=1.36$ for a thickness of $26.5 \mathrm{~nm}$ ). Conversely, the refractive index reached a value of 1.45 and a thickness of $39.5 \mathrm{~nm}$ for $\mathrm{BaCl}_{2}$. In the latter case, the layer investigated by laser beam was more compact and had a low percentage of entrapped water leading to a high refractive index close to the value encountered in the literature for bulky polymer.

\section{Conclusion}

Reflectometric measurements and AFM analysis were used to investigate the effect of experimental physicochemical parameters on multilayered film properties composed of a strong cationic polyelectrolyte (MADQUAT) and a weak anionic polyelectrolyte (PAA). These parameters were: the number of adsorbed layers, sodium chloride salt concentration and type of salts (monovalent or divalent ions). During the build-up of polyelectrolyte multilayers up to 24 bilayers, reflectometric output exhibits a special trend directly linked to the variation in the refractive index of the film. The refractive index changes progressively from a value close to that of water to a reference value for bulk polymeric materials. This variation is corroborated by one of our previous AFM studies showing extensive modification in surface morphology from peaks covering the surface to a smoother film. Adsorbed amount and film surface morphology both can be tuned by adjusting the number of adsorbed layers. Salts added in polymer solution influence electrostatic interactions and then modify the construction of the film. This induces a change in the refractive index, thickness and morphology of the film. While 20 alternate deposition steps are necessary to obtain a smooth film with a refractive index close to a pure polymer layer, only 5 bilayers are necessary in the presence of barium ions. Therefore the increase in ionic concentration increases polymer uptake to a lesser degree. Even if these films built-up in several experimental conditions exhibit different surface morphologies and refractive indexes, further investigation is needed to examine their stability and permeability.

\section{References}

[1] G. Decher, Science 277 (1997) 1232.

[2] G. Decher, J.B. Schlenoff, Multilayers Thin Films, Wiley-VCH, Weinheim, 2003.

[3] S.T. Dubas, T.R. Farhat, J.B. Schlenoff, J. Am. Chem. Soc. 123 (2001) 5368.

[4] P. Stroeve, V. Vasquez, M.A.N. Coelho, J.F. Rabolt, Thin Solid Films 284-285 (1996) 708.

[5] F. van Ackern, L. Krasemann, B. Tieke, Thin Solid Films 327-329 (1998) 762.

[6] R.V. Klitzing, B. Tieke, Adv. Polym. Sci. 165 (2004) 177.

[7] L. Krasemann, B. Tieke, Langmuir 16 (2000) 287.

[8] A.A. Antipov, G.B. Sukhorukov, H. Mohwald, Langmuir 19 (2003) 2444.

[9] J.J. Harris, J.L. Stair, M.L. Bruening, Chem. Mater. 12 (2000) 1941.

[10] A. Toutianoush, W. Jin, H. Deligoz, B. Tieke, Appl. Surf. Sci. 246 (2005) 437.

[11] U.K. Aravind, J. Mathew, C.T. Aravindakumar, J. Membr. Sci. 299 (2007) 146

[12] L. Ouyang, R. Malaisamy, M.L. Bruening, J. Membr. Sci. 310 (2008) 76.

[13] G.B. Sukhorukov, E. Donath, Polym. Adv. Technol. 9 (1998) 759.

[14] G.B. Sukhorukov, E. Donath, H. Lichtenfeld, E. Knippel, M. Knippel, A. Budde, H. Möhwald, Colloids Surf., A 137 (1998) 253. 
[15] V. Kozlovskaya, S.A. Sukhishvili, Macromolecules 39 (2006) 6191.

[16] X. Qiu, S. Leporatti, E. Donath, H. Mohwald, Langmuir 17 (2001) 5375.

17] C. Buron, PhD. Thesis, University of Franche-Comte, 2004

18] J.C. Dijt, M.A. Cohen Stuart, G.J. Fleer, Adv. Colloid Interface Sci. 50 (1994) 79.

[19] T. Roques-Carmes, F. Membrey, C. Filiâtre, A. Foissy, J. Colloid Interface Sci. 245(2002) 257.

[20] D. Kovacevic, S. van der Burgh, A. de Keizer, M.A. Cohen Stuart, Langmuir 18 (2002) 5607.

[21] C.C. Buron, C. Filiâtre, F. Membrey, H. Perrot, A. Foissy, J. Colloid Interface Sci. 296 (2006) 409.

[22] C.C. Buron, F. Membrey, C. Filiâtre, A. Foissy, Colloids Surf., A 289 (2006) 163.

[23] J.A. De Feijter, J. Benjamins, F.A. Veer, Biopolymers 17 (1978) 1759

[24] F. Boulmedais, M. Bozonnet, P. Schwinté, J.-C. Voegel, P. Schaaf, Langmuir 19(2003) 9873.

[25] L. Richert, Y. Arntz, P. Schaaf, J.-C. Voegel, C. Picart, Surf. Sci. 570 (2004) 13.

[26] C. Picart, P. Lavalle, P. Hubert, F.J.G. Cuisinier, G. Decher, P. Schaaf, J.-C. Voegel, Langmuir 17 (2001) 7414
[27] E. Hubsch, V. Ball, B. Senger, G. Decher, J.-C. Voegel, P. Schaaf, Langmuir 20 (2004) 1980.

[28] C.C. Buron, C. Filiatre, F. Membrey, C. Bainier, D. Charraut, A. Foissy, Colloids Surf., A 305 (2007) 105

[29] C.C. Buron, C. Filiatre, F. Membrey, C. Bainier, D. Charraut, A. Foissy, J. Colloid Interface Sci. 314 (2007) 358

[30] G. Decher, J.D. Hong, J. Schmitt, Thin Solid Films 210/211 (1992) 831.

[31] G.J. Fleer, M.A. Cohen Stuart, J.M.H.M. Scheutjens, T. Cosgrove, B. Vincent, Polymers at Interfaces, Chapman and Hall, London, 1993.

[32] N.G. Hoogeveen, M.A. Cohen Stuart, G.J. Fleer, J. Colloid Interface Sci. 182 (1996) 133.

[33] R.A. McAloney, M. Sinyor, V. Dudnik, M.C. Goh, Langmuir 17 (2001) 6655.

34] B. Schoeler, G. Kumaraswamy, F. Caruso, Macromolecules 35 (2002) 889.

[35] I. Pochard, P. Couchot, A. Foissy, Colloid Polym. Sci. 276 (1998) 1088.

[36] S. Koda, H. Nomura, M. Nagasawa, Biophys. Chem. 18 (1983) 361. 